Very Short Introductions online

You are looking at 1-1 of 1 items for: SOC00610

\title{
Organized Crime: A Very Short Introduction
}

Georgios A Antonopoulos and Georgios Papanicolaou

Print Publication Year: 2018 Published Online: Feb 2018 Publisher: Oxford University Press

ISBN: 9780198795544 eISBN: 9780191836879

DOI: 10.1093/actrade/9780198795544.001.0001

Item type: book

Organized Crime: A Very Short introduction examines the people involved in organized crime and questions whether the term 'organized' is used to evoke the image, operations, and power of a legitimate organization, such as a corporation. Are there particular crimes where the label 'organized crime' fits, or can any crime be 'organized'? What happens when organized crime extends beyond borders? Using examples from across the globe, it analyses different cultural traditions of organized crime, such as the Mafia, Yakuza, and Triads, and the nature of organized crime, from arms trafficking and drug dealing to extortion. Finally, it explores the methods and agencies in place to control and prevent organized crime. 